East African Medical Journal Vol. 86 No. 5 May 2009

ADHERENCE TO ANTIRETROVIRAL DRUG THERAPY BY ADULT PATIENTS ATTENDING HIV / AIDS CLINIC AT A KENYAN TERTIARY HEALTH INSTITUTION

N.C. Talam, B.Ed, MPH, HIV Prevention Manager, South Rift Valley, PEPFAR, Walter Reed Project HIV Program, Kericho, Kenya, P. M. Gatongi, BVM, MSc, PhD, Senior Lecturer, J. K. Rotich, BSc, MSc, PhD, Professor of Biostatics, Department of Epiodemiology and Nutrition, School of Public Health, Moi University, P.O. Box 4606, Eldoret, Kenya and S. Kimaiyo, MBChB, MMed, Senior Lecturer Department of Medicine, School of Medicine, Moi University, P.O. Box 4606, Edoret, Kenya

Request for reprints to: N.C. Talam, Department of Epidemiology and Nutrition, School of Public Health, Moi University, P. O. Box 4606, Eldoret, Kenya

\title{
ADHERENCE TO ANTIRETROVIRAL DRUG THERAPY BY ADULT PATIENTS ATTENDING HIV/AIDS CLINIC AT A KENYAN TERTIARY HEALTH INSTITUTION
}

\author{
N. C. TALAM, P. M GATONGI, J. K. ROTICH and S. KIMAIYO
}

\begin{abstract}
Objective: To determine antiretroviral drug adherence levels of HIV/AIDS in adult patients.

Design: A cross sectional study.

Setting: Moi Teaching and Referral Hospital (MTRH), Eldoret, Kenya.

Subjects: Three hundred and eighty four HIV/AIDS adult patients who attended HIV/AIDS clinic in MTRH for antiretroviral treatment and had been on treatment for at least three months as confirmed by clinicians.

Results: Three hundred and eighty four respondents participated in this research; two third of whom were females $(68 \%)$ and a third were males $(32 \%)$. Fifty two per cent of these had attained secondary or post secondary education. The mean age was $36.1 \pm 8.5$, years and ranged $18-63$ years. While $93.5 \%$ of the participants adhered to clinic appointments, only $43.2 \%$ adhered to taking the drugs as per time schedule. Conclusion: Adherence to time of taking medications was low and could result in reduced efficacy.
\end{abstract}

\section{INTRODUCTION}

In Kenya, AIDS is a rapidly growing public health problem. In less than a decade, AIDS has evolved from a fulminant, rapidly fatal illness into a chronic disease. Already, more than 2 million people are estimated to have been infected in Kenya as from 1985 when the first case of AIDS was recognised (1). In Moi Teaching and Referral Hospital (MTRH), HIV / AIDS patients receive free ARVs through Academic Model for Prevention and Treatment of HIV / AIDS (AMPATH) programme.

Antiretroviral medications are effective but are complex and require near perfect adherence to the prescribed regimen to achieve and maintain their efficacy. In order to be effective, treatment of HIV / AIDS with antiretroviral requires 100\% rate of adherence $(2,3)$. Several studies have demonstrated that, the consequences of missed doses or poor adherence to HAART is critical, with evidence of an increasing viral load after only two days of default followed by development of mutant viral strains $(4,5)$. As blood drug levels fall below a critical point, the regimens inhibitory effect on viral replication decreases and this allows for increases in viral load. Studies have shown that, among the patients suffering from HIV / AIDS, only about one third take their medications as prescribed while the rest do not (6).

The aim of this study was to determine adherence levels among HIV / AIDS adult patients using timing of medications and keeping of clinic appointments fordrug refills as key indicators of adherence. It also determined the association between the two indicators.

\section{MATERIALS AND METHODS}

Study area and design:This study was conducted at Moi Teaching and Referral Hospital (MTRH), Eldoret, Kenya from May to July 2005. It was a cross-sectional study and it examined demographic and other characteristics of the respondents and antiretroviral drug adherence levels. 
Study population: The study population consisted of HIV / AIDS adult patients on ARVs and attending AMPATH HIV clinic at MTRH. Expectant mothers were excluded from the study as they were on a different programme.

Data collection: Data collection was done after receiving approval letter from Institutional Research and Ethics Committee (IREC) from Moi University/Moi Teaching and Referral Hospital (MTRH). Three hundred and eighty four adult patients (both males and females of 18 years and above) were interviewed after the purpose of the study was explained to them and were assured of confidentiality. The researchers worked in association with the clinicians in the HIV / AIDS clinic. Clinicians identified patients who had been on ARV treatment for at least three months. Once ARV drugs had been prescribed, the patient moved to the pharmacy to collect them. It was at this point that the researchers, by use of interviewadministered questionnaires interviewed the patients. The interview was continued on consecutive patients until the determined sample of 384 was attained, The questionnaire sought demographic data and ARV drug adherence levels of the patients based on timing of taking drugs. Information on adherence to clinic appointments was obtained from hospital health records.

Data analysis: Data generated from the questionnaire were analysed using statistical package for social scientist (SSPS) version 10.0 for frequencies, crosstabulation and chi-square at the significant level of $\mathrm{p}>0.05$.

\section{RESULTS}

Demographic and other characteristic of respondents: Majority of the respondents on ARVs were females $261(68 \%)$. More than half of the respondents $200(52 \%)$ had attained secondary or post secondary education. The respondents were aged between 18-63 years (mean age $36.1 \pm 8.5$ years). Half of the participants $198(51.6 \%)$ were between the age groups of 26-35 years. Majority of the respondents were married 272 $(70.8 \%)$. One hundred and four $(84.6 \%)$ of the males were married as compared to $168(64.4 \%)$ of females. More than half $214(55.7 \%)$ of the participants lived outside Eldoret Municipality. However, both males and females had comparable place of residence $(p=0.569)$ and education levels $(p=0.921)$. The age distribution, marital status, employment status, time of working between the two sexes were significantly different $(p=0.000)$ respectively.

Antiretroviral drug adherence levels: The overall adherence level based on timing of medications was $43.2 \%$ (45.5\% for males and $42.1 \%$ for females respectively). On keeping of clinic appointments, the overall adherence level was 93.5\% (95.1\% and $92.7 \%$ for males and females respectively - Table 1). Overall, there was no association between adherence based on timing of taking drugs and adherence based on keeping of clinic appointments among all the respondents $\left(X^{2}=0.2480, P=0.618\right)$. The same result was true for males and females (Table 2). Fewer males failed to keep clinic appointments hence the interpretations of the Chi-square in Table 2 is unreliable. However, Cochran and Daniel $(7,8)$ suggested that when $n \geq 40$, an expected cell frequency as small as 1 can be tolerated.

Table 1

Drug adherence levels for all respondents based on timing of taking drugs and keeping of clinic appointments

\begin{tabular}{|c|c|c|c|c|c|c|c|c|}
\hline $\begin{array}{l}\text { Kept clinic } \\
\text { appointment }\end{array}$ & $\begin{array}{l}\text { Took } \\
\text { No. }\end{array}$ & $\begin{array}{l}\text { drugs on time } \\
(\%)\end{array}$ & $\begin{array}{l}\text { sche } \\
\text { No. }\end{array}$ & $\begin{array}{l}\text { aled } \\
(\%)\end{array}$ & No. & $(\%)$ & $X^{2}$ & P-value \\
\hline Yes & 154 & 40.1 & 205 & 53.4 & 359 & 93.5 & & \\
\hline No & 12 & 3.1 & 13 & 3.4 & 25 & 6.5 & 0.2480 & 0.618 \\
\hline Total & 166 & 43.2 & 218 & 56.3 & 384 & 100 & & \\
\hline
\end{tabular}


Table 2

Drug adherence levels for males and females based on timing of taking medications and keeping of clinic appointments

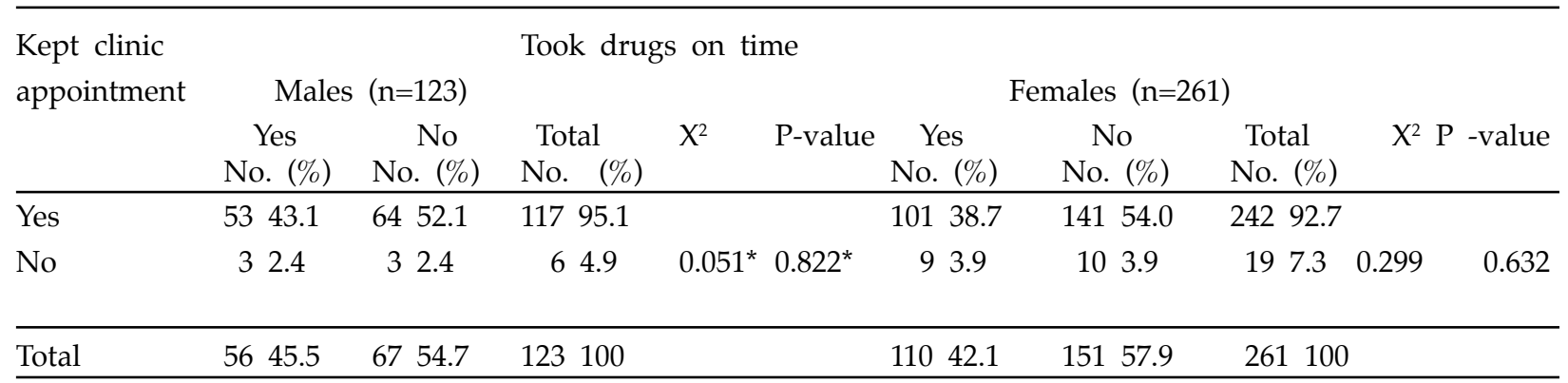

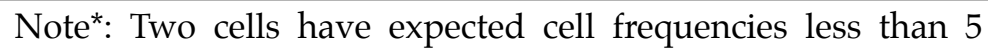

\section{DISCUSSION}

The measurement of medication adherence is a difficult endeavor both in clinical care and research settings. Quantifying the levels and types of medication adherence involving patient care has been the focus of many studies resulting in theidentification of multiple direct and indirect measures $(9,10)$. It is difficult to measure adherence in the outpatient setting with absolute precision and accuracy (11). While there may be no gold standard with which to measure adherence, there are several strategies that have been used to assess adherence which includes, clinician assessment, pill counts, prescription refills, biological assays, Medication Event Monitoring System (MEMS), Directly Observed Therapy (DOT) and Self report (SR)(12-15). Most studies of adherence use one or more of these tools.

In the current study, a combination of self reports by patients on timing of taking ARV drugs and information from hospital health records on keeping of clinic appointments for prescription refills by the same patients was used as key indicators. Previous studies have found self-reports to be a useful tool in measuring adherence and it is very reliable when patients report on non-adherence (10). However several studies suggest that self-reports tend to overestimate actual adherence $(10,16)$.

The findings of this study established that the overall antiretroviral drug adherence level of all the respondents was $43.2 \%$ and $93.5 \%$ based on keeping to scheduled timing of medication and keeping scheduled clinicappointments respectively (Table1). Theadherence levels of the respondents based on keeping to timing of medication were very low. However, it was difficult to establish if the patients took drugs at a later time or failed completely. This closely corresponds to the study carried on Zidovudine adherence among individuals with HIV infection, which gave an adherence level of $42 \%$ (17). Timing of doses of ARVs is very critical because, as drug levels fall below a critical point, the regimens inhibiting effect on viral replication maylessen allowing for increase in the viral load $(4,5)$.

Adherence levels based on timing of taking drugs for males, 56(45.5\%) was slightly higher than that for females, $110(42.1 \%)$, (Table 2). This could be explained by the fact that women were very busy with household responsibilities that could have disrupted their adherence to timing of taking drugs. This could be related to the fact that more women than men were divorced, widowed or separated. Studies have shown that patients with supportive friends and families tend to adhere to ARVs better than those without such supports $(18,20)$.

Though adherence level of $93.5 \%$ for clinic appointments as shown in Table 1 , was close to the ideal expectations, it is important to note that patients may take home adequate amount of drugs but may not take them appropriately due to complexities of prescribed regimens and difficulties in understanding instructions. This high level of adherence indicated that the respondents tried hard to adhere to the scheduled clinic visits for prescription refills possibly because they received free ARVs. Studies in South Africa indicated that indigent patients recruited from the greater Cape Town area, receiving free therapy on clinic trial took $93.5 \%$ of their medication as measured by clinic based pill count (21). A study in Senegal reported $87.9 \%$ adherence among poor patients receiving free ARVs (22).

In this current study, males were more adherent to clinic appointments $(95.1 \%)$ than females $92.7 \%$. Again as for the keeping of treatment time, the demanding domestic responsibilities of women could have contributed to lower adherence. This confirmed the role of patient characteristics and attitudes regarding HAART adherence, and demonstrated that men were more adherent than women (23).

This study established that there was no associationbetweentiming ofmedicationsand keeping of clinic appointments among the respondents. Other studies have shown that patients may keep to clinic 
appointments and take home adequate prescribed doses but may not take them at appropriate times $(10,24)$.Achieving $100 \%$ adherence for any treatment is therefore not realistic. This is particularly difficult for patients living in rural areas where routine activities are not time bound and therefore of little help as reminders to the patients to take their prescribed drugs.

In conclusion, the overall adherence levels based on timing of taking drugs was very poor compared to keeping of clinic appointments among all respondents and between males and females. There was no significant relationship between timing of medications and keeping of clinic appointments. It was recommended that there was need to educate patients on importance of adhering to drug administration. Similarly, it was important toestablish the underlying cause of disparity between refills and time of taking drugs.

\section{ACKNOWLEDGEMENTS}

We thank Prof. W. Odero, of the School of Public Health, Maseno University, for constructive criticism. We also thank the administration and management of Moi Teaching and Referral Hospital for allowing this research to be carried out in the hospital and the clients who agreed to participate in the research and to clinicians in AMPATH for their role in identifying the patients for this study.

\section{REFERENCES}

1. Republic of Kenya. Guidelines on Tuberculosis and Leprosy control. Ministry of Health, Nairobi. 2003.

2. Henry, K. The case for more cautions, patient-focused antiretroviral therapy. Ann. Intern. Med. 2000; 132: $306-311$.

3. Von, Korf, M. Collaborative management of chronic illness. Ann. Intern. Med. 1997; 127: 1097 - 1102.

4. Blaschke, T.F. Non adherence and resistance to protease inhibitors. Fourth conference on retroviruses and opportunistic infections 1997; Chicago, Illinois.

5. Vonhove, G., Schapiro, J., Winters, M.A., et al. Patient adherence and drug failure in protease inhibitor monotherapy (letter). J. Amer. Med. Assoc. 1996; 276: 1955-1956.

6. Bendell, S.E. Discrepancies in the use of medications; their extent and predictors in an outpatient practice. Archives Intern. Med. 2000; 160: 2129-2134.

7. Cochran, W.G. Some methods of strengthening the common chi-square test, Biometric, 10 (1954), 417 -451 .

8. Daniel, W.W. Biostatistics. A foundation for analysis in health sciences, Sixth Edition, John Wiley \& Sons Inc, New York, 1995, Chapter 12, pp 526.
9. Miller, K.G., and Hags, R.D. Measuring adherence to antiretroviral medications in clinical trials. HIV Clin. Trials. 2000; 1: $36-46$.

10. Melbourne, K.M., Gelekto, S.M., Brown, S.L., et al. Medication adherence in patients with HIV infection: A comparison of two measurement methods. AIDS Reader. 1999; 9: 329 - 338.

11. Flexner, C. Practical treatment issues and adherence. Challenges from the clinic. Clinical care options for HIV treatment issues. www.healthcg.com/hiv/treatment/ icacac 97/adherence/print.html) 1997.

12. Besch, C.L. Adherence in clinical trials. AIDS. 1995; 9:1-10.

13. Bonds, W.S. and Hussar D. A. Detection methods and strategies for improving medication adherence. A.M. Hosp. Pharm. 1991; 48: 1978 - 1988.

14. Cramer, J.A., Mattson, R.H., Prevey, M.L. et al. How often is medication taken as prescribed? A novel assessment technique. J. Amer. Med. Assoc. 1988; 261: 3273 - 3277 .

15. Urquhart J. Role of patient adherence in clinical pharmacokinetics: A review of recent research. Pharmacokinetics. 1994; 27: 202 - 215.

16. Arnsten, J., Demas, P.A., Farzadegan, H., et al. Antiretroviral therapyadherenceand viralsuppression in HIV-infected drug users: comparison of self-report and electronic monitoring. Clin. Infect. Dis. 2001; 33: 1417-1423.

17. Muma, R.D., Ross, M.W., Parcel, G., Pollard, P. Zidovudine adherence among individuals with HIV infection. AIDS Care. 1995; 7: 439-447.

18. Paterson, D., Swindells, S., Mohr, J., et al. Adherence to protease inhibitor therapy and outcomes in patients with HIV infection. Ann. Intern. Med. 2000; 133:21-30.

19. Morse, E.V.Determinants of subject compliance within an experimental anti-HIV drug protocol. Socio Sci. Med. 1991; 32:1161-1167.

20. Stall, R. Decisions to get HIV tested and to accept antiretroviral therapies among gay/bisexual men: Implications for secondary prevention efforts. J. Acq. Immune Deficiency Syndromes and Human Retrovirology 1996; 11:151-160.

21. Catherine, O., David, R., Bangsberg, M. B. and Robin W. Adherence is not a barrier to successful antiretroviral therapy in South Africa. Lippincott Williams and Wilkins Cape Town. AIDS. 2003, 17:13691375.

22. Laurent, C., Diakahte, N., Gueye, N.F.N., et al. The Senegalese government's highly active antiretroviral therapy initiative: 18 month follow-up. AIDS. 2000; 16: 1363 - 1370 .

23. Wenger, N.Patient characteristics and attitudes associated with anti-retroviral (AR) adherence. Abstract No.98. presented at the VI conference on retrovirus and opportunistic infections Washington DC. 2002

24. Chesney,M.A.Self-reported adherencetoantiretroviral medications among participants in HIV clinical trials: the AATG adherence instruments. AIDS Care. 2000; 12:255-266 